\title{
Amino acid substitutions in the E2 glycoprotein of Sindbis-like virus XJ-160 confer the ability to undergo heparan sulfate-dependent infection of mouse embryonic fibroblasts
}

\author{
Wuyang Zhu' ${ }^{1}$, Shihong $\mathrm{Fu}^{1}$, Ying $\mathrm{He}^{1}$, Jinping $\mathrm{Li}^{2}$, Guodong Liang ${ }^{1 *}$
}

\begin{abstract}
We have recently demonstrated an essential role of the domain of 145-150 amino acid in the E2 glycoprotein of Sindbis virus in the interaction with cellular heparan sulfate (HS) and in the infection of mouse embryonic fibroblasts (MEF) cells. In this study, we constructed and characterized the mutants of Sindbis-like virus XJ-160 in which Tyr-146 and/or Asn-149 in the E2 glycoprotein had been substituted with His and Arg, respectively. Unlike parental virus XJ-160, mutants with either or both substitutions were able to infect wild-type mouse embryonic fibroblasts (MEF-wt) or MEF-Epi-- cells which produce mutant HS. Significantly more infectious particles were released from MEF-wt than from MEF-Epi- cells. The mutant virus with both substitutions release was inhibited by pre-incubation of virus with heparin or pre-treatment of BHK-21 cells with HS-degrading enzyme. Both XJ-160 and the mutant viruses retained substantial neurovirulence in suckling mice. Our findings provide further support to the importance of positively charged residues in the HS-binding site of E2 in mediating Sindbis virus infection of MEF cells.
\end{abstract}

\section{Findings}

Sindbis virus (SINV) is considered the prototype of Alphavirus genus, Togaviridae family [1,2]. Nearly 30 members of the genus are widely distributed in all continents except in the Antarctic. Sindbis virus is an enveloped virus with an $11.5 \mathrm{~kb}$ genome of single stranded RNA. The viral genome with a 5' terminal methylguanylate cap and a 3' terminal polyadenylate tail encodes four nonstructural proteins (nsP1-4) and three mature structural proteins (capsid, E2 and E1). Based on the divergence of nucleotide sequencing and biological characteristics, Sindbis virus can be divided into two groups, SINV and Sindbis-like virus (SINLV) [3]. SINV YN87448 and SINLV XJ-160 were isolated from a pool of Anopheles mosquitoes collected in Xinjiang and from a female patient with fever in Yunnan, China $[4,5]$.

Heparan sulfate (HS) is a complex polysaccharide expressed in the form of proteoglycans on the surfaces

\footnotetext{
* Correspondence: gdliang@hotmail.com

'State Key Laboratory for Infectious Disease Prevention and Control (SKLID), Institute for Viral Disease Control and Prevention, China CDC, Beijing, China Full list of author information is available at the end of the article
}

of a wide range of invertebrate and vertebrate cells. Recently, HS has been found to be involved in the infection and pathogenicity of SINV [6,7] and other alphaviruses, such as Venezuelan encephalitis virus (VEEV), Semliki Forest virus (SFV) and Ross River virus (RRV) $[8,9]$. These investigations indicate that HS-dependent infection is an adaptation through the mutation for positively charged amino acid (aa), which frequently arise in laboratory strains during repeated passaging culture, and that wild-type strains of SINV might not bind well to HS. Besides alphaviruses, HS has been shown to serve as a receptor of a number of viruses, including herpes simplex virus (HSV) [10], human immunodeficiency virus type 1 (HIV-1) [11], adeno-associated virus type 2 (AAV2) [12], respiratory syncytial virus (RSV) [13], foot-and-mouth disease virus (FMDV) [14], and human papillomavirus type 11 [15].

Based on the difference in HS-dependent infectivity between YN87448 virus and XJ-160 virus, we have confirmed that interaction of E2 protein with HS is crucial for cellular infection of SINV [16]. Importantly, specific interaction of E2 peptide from YN87448 with heparin 
further suggests that the domain of 145-150 amino acid (aa) from the E2 gene may be a molecular basis for the specific interaction of SINV with cellular HS. Alignment of the E2 glycoprotein sequences from YN87448 and $\mathrm{XJ}-160$ revealed the differences at the domain where the two positively charged aa (His and Arg at 146 and 149, respectively) of SINV YN87448 are neutral aa in SINLV $\mathrm{XJ}-160$. This may explain that SINLV XJ-160 is not HSdependent in infection of cells due to lacking of the two basic amino acids in the second HS-binding domain. Specific interaction of the peptide containing 145-150 aa from YN87448 E2 gene with heparin and no binding of the corresponding peptide from the of XJ-160 E2 gene to heparin further strengthened this speculation. However, the effects of E2-146Tyr and E2-149Asn on HS binding of Sindbis virus in the context of virus-RNA remain to be confirmed.

To find out the effect E2-146Tyr and E2-149Asn on HS-dependent infecion, three mutant viruses, BR-146 H containing point mutation $146 \mathrm{Y}-\mathrm{H}, \mathrm{BR}-149 \mathrm{R}$ containing $149 \mathrm{~N}-\mathrm{R}$ and BR-HR containing both mutations were generated by in vitro transcription and electroporation method as previously described $[16,17]$. The results of immunofluorescence assay (IFA) and plaque assay indicated that XJ-160 virus was capable of assembling infectious particles in spite of different site-directed mutation at residue E2-146 or residue E2-149, and that all the mutant viruses displayed plaque morphologies similar to those formed by XJ-160, although the mutants seem to form bigger plaques (Additional file 1, Figure 1). In addition, determination of the titers demonstrated that BR-HR virus released more infectious particles than either parental virus XJ-160 or other two mutants (Additional file 2, Figure 2).

To investigate the correlation between the mutants and cellular HS, we have compared infectivity of the mutants and XJ-160 virus in wild-type mouse embryonic fibroblast (MEF-wt) cells with that in two mutant MEF cell lines. The MEF-Ext $t^{-/}$is derived from the mice that are deficient in one of the HS polymerases, EXT1 [18], and the MEF-Epi- ${ }^{-1}$ is generated from mice that are lacking one of the modifications enzymes, glucuronyl C5-epimerase [19]. Characterization of the MEF cells generated from the mutant embryos illustrated that the MEF-Ext ${ }^{-/-}$ expressed a HS that is normal in composition, but is significantly shorter in chain length $(20 \mathrm{kDa})$, in comparison to the wild-type $\mathrm{HS}(70 \mathrm{kDa})[20]$; while the MEF-Epi $i^{-1-}$ cells expressed a full-length HS with a defective structure, e.g. lacking iduronic acid units and 2-Osulfation accompanied with increased $\mathrm{N}$-sulfation [21]. And three MEF cell lines (MEF-wt, MEF-Epi-' and MEF-Ext $t^{--}$) used in this study was kindly provided by Dr Jin-ping Li, University of Uppsala, Sweden. MEF$E x t^{-1-}$ cells were resistant to all of viruses, likely due to the shorter HS chains expressed on their cell surface, indicating that the chain length of HS on cell surface is critical for viral attachment. In contrast, YN87448 and all the mutants were able to infect MEF-wt and MEF$\mathrm{Epi}^{-1-}$ cells as demonstrated by IFA ( Figure 1a). These results suggest that substitution at residue E2-146 or residue E2-149 could help XJ-160 virus to overcome the MEF infection block by discriminating cellular HS.

It should be point out that either the mutants or YN87448 displayed considerably weaker infectivity in MEF-Epi $i^{-1-}$ cells in comparison to that in MEF-wt cells (Figure 1a). Quantification of the mutant viruses in culture medium clearly revealed different kinetics of viral reproduction in MEF- $w t$ cells and MEF-Epi ${ }^{-1-}$ cells. All the mutants reach growth plateau approximately $84 \mathrm{~h}$ post-infection (h p. i.), but the reproduction ability varies, in the order of BR-HR, BR-149R and BR-HR in either MEF-wt cells or MEF-Epi ${ }^{-1-}$ cells (Figure 1b,c). More importantly, each virus released 2-3 order of magnitude more infectious particles in MEF- $w t$ cells than that in MEF- Epi $i^{-/-}$cells (Figure 1b,c). In consideration of the fact that $2-O$-sulfated iduronic acid residue is commonly found in the HS sequences that interact with proteins (16), the reduced infectivity of the viruses to MEF-Epi $i^{-1-}$ cells in comparison to the MET-wt cells is likely due to the structural alterations of the surface HS that has a weaker interaction with E2 protein, suggesting that the fine structure of HS on cell surface is critical for viral attachment and infection. Indeed, the mutant HS from MEF-Epi ${ }^{-1-}$ exhibited an aberrant interaction with growth factors. Further studies to test the infection of the viruses on a 2-O-sulfotransferase mutant cell may provide additional information to this end.

Heparin, an analog of HS, is commonly used as a replacement of HS in in vitro experiments [22] and has been reported to be able to block Sindbis virus to infect and form plaques in cells [7]. Bacterial produced heparinase I that cleaves heparin and cellular HS has been commonly used to remove cell surface HS for various biological studies [23]. To further identify the functions of substitution at E2-146 or E2-149 on HS-dependent infection, we applied heparin or heparinase I to preincubate virus or BHK-21 cell, respectively. Pre-incubation of heparin with the viruses resulted in different inhibition of viral infection in BHK-21 cells. BR-149R and BR-HR showed a about inhibition of $20 \%$ and $50 \%$ at the concentration of $100 \mu \mathrm{g} / \mathrm{ml}$, while addition of heparin had marginal effect on the plaque formation of BR-146 H (Figure 2a). Together with the similar effect of heparinase I treatment (Figure 2b), we can conclude that the simultaneous substitutions at E2-146Tyr and E2-149Asn enhance HS-dependent infection by XJ-160, especially substitution of E2-149 N-R plays an important role in HS-dependent infection. In the absence of crystal 


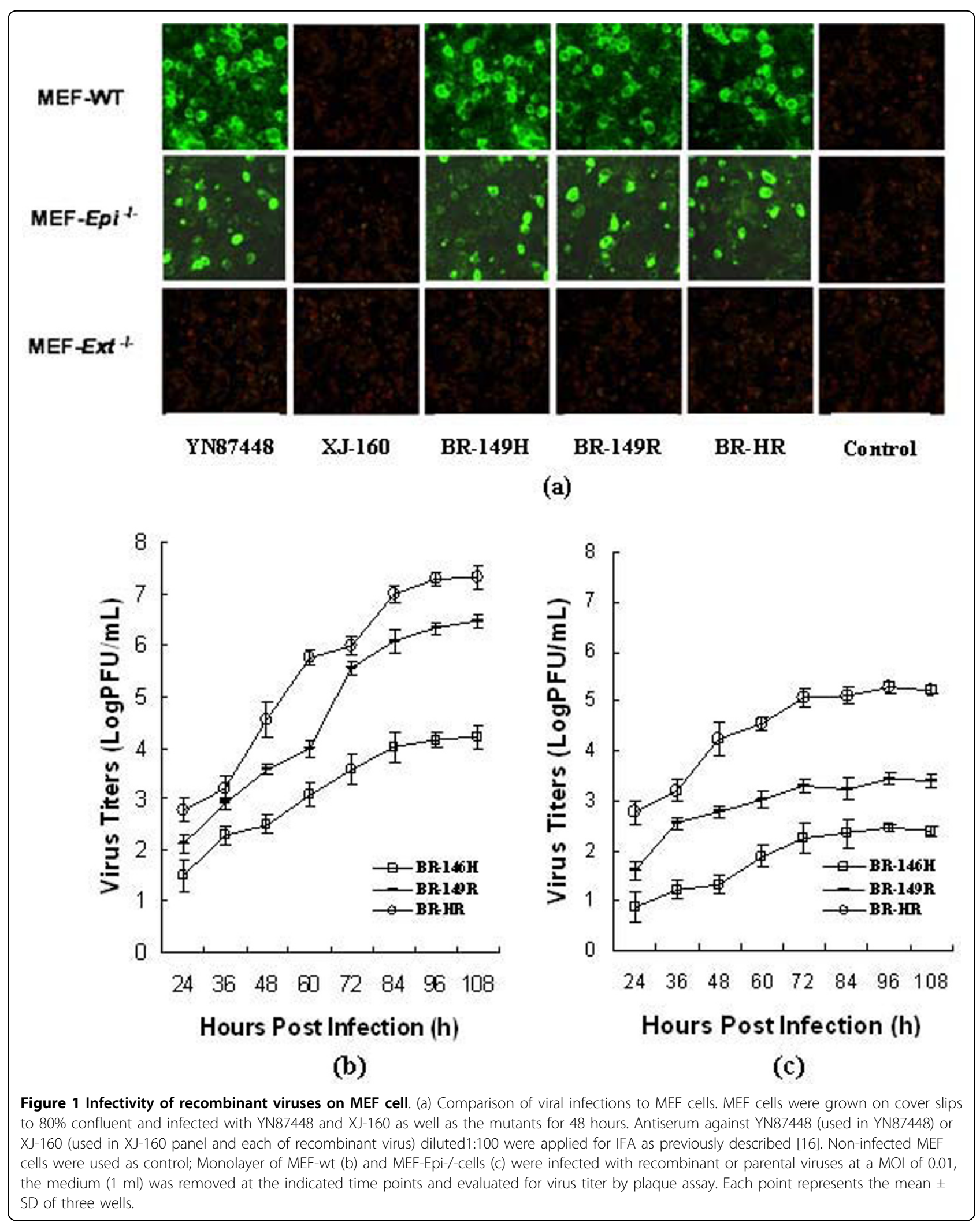




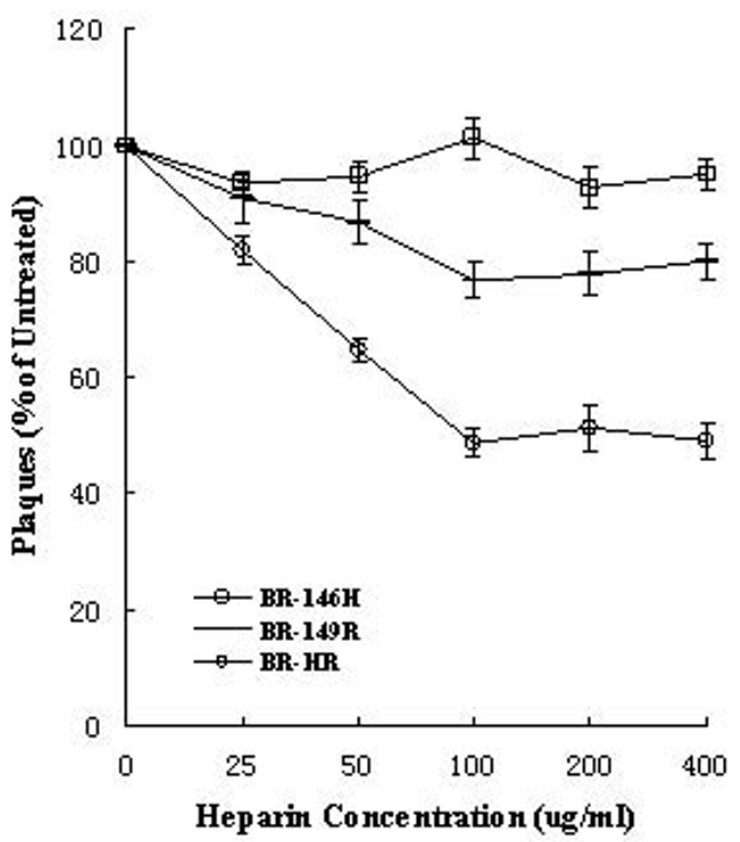

(a)

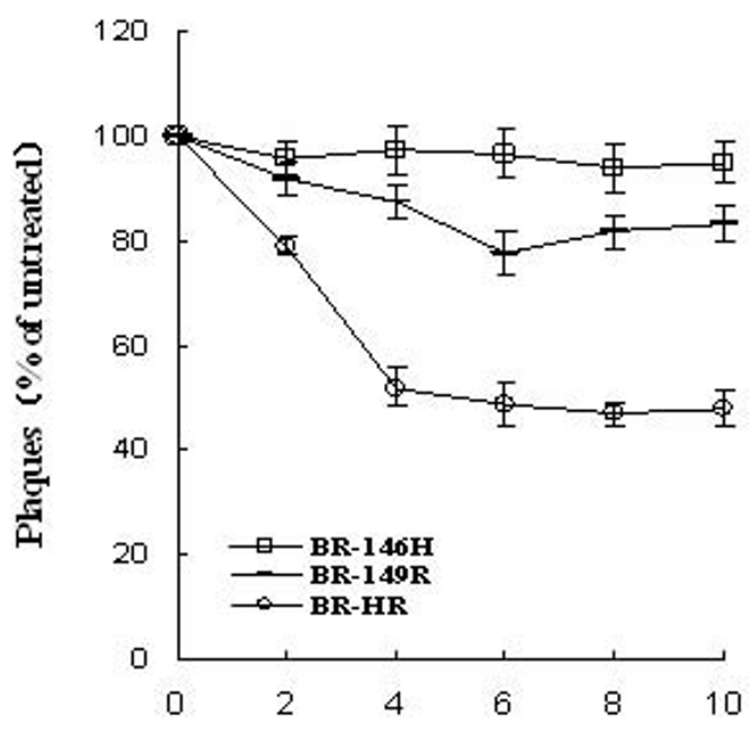

Heparinase I (Units/mL)

(b)

Figure 2 Effect of heparin or heparinase I treatment on plaque formation of mutant viruses. (a) Viruses diluted to 100-200 PFU/200 $\mu$ l were incubated with heparin at the concentrations indicated for $1 \mathrm{~h}$ at $37^{\circ} \mathrm{C}$. Then the plaque assay was performed on BHK-21 cells as previously described [16]. (b) Confluent BHK-21 cell monolayers were treated with heparinase I at the concentrations as indicated. After washing three times with PBS, the cells were infected with viruses diluted to 100-200 PFU in $200 \mu \mathrm{l}$. Plaque formation was analyzed as described.

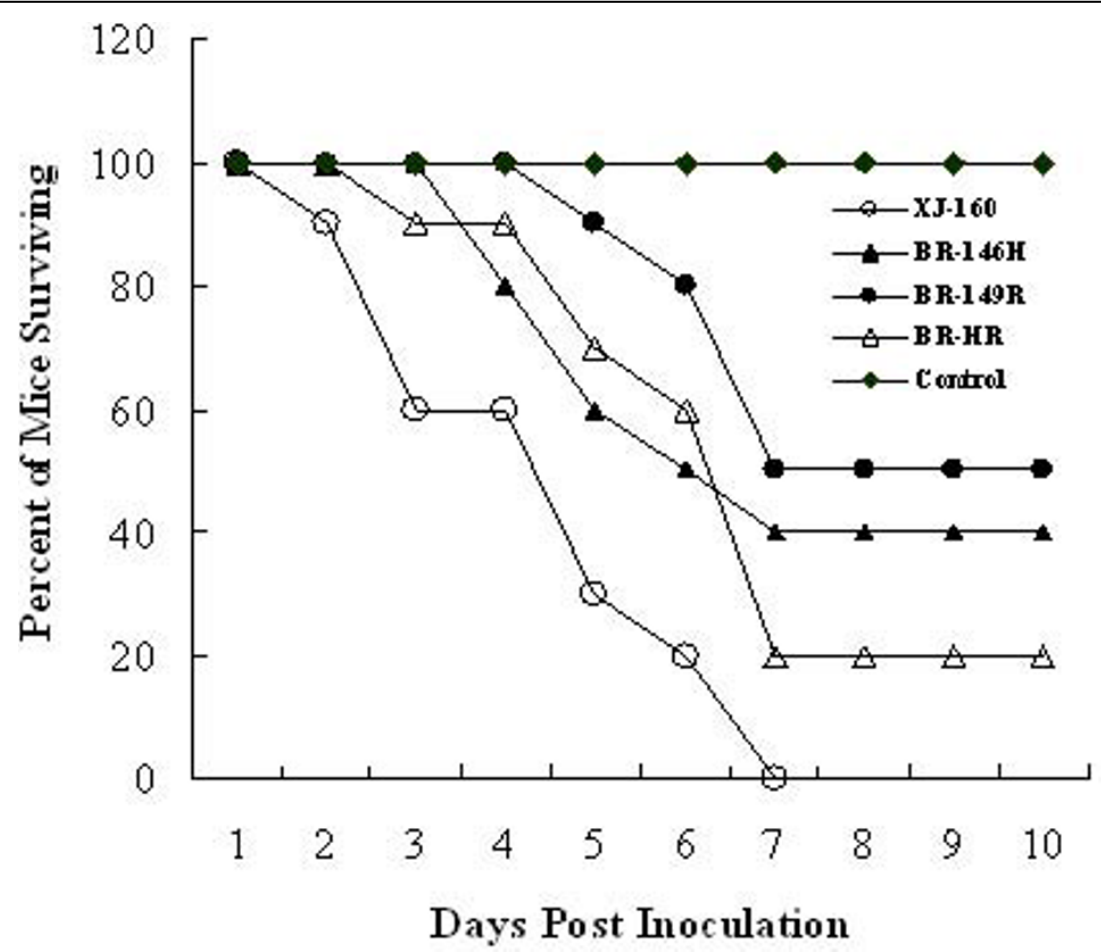

Figure 3 Neurovirulence of the viruses for suckling mice. Suckling mice (three days old) were inoculated intracerebrally with $30 \mu l$ of $10^{3}$ PFU/ml recombinant or parental viruses; equal volume of Eagle's fortified with $1 \%$ fetal bovine serum was used as control. 
structural information about the Alphavirus E2 glycoprotein, it is difficult to predict that any particular amino acid is part of a binding site for HS or even that the amino acid is exposed on the surface of the virion. However, together with the notion that binding sites of SINV to HS are composed of the linear HS-binding domains and the scattered positively charged aa [16], our data demonstrate the importance of positively charged residues in the HS-binding domain of E2 in mediating SINV infection.

Increased binding of alphaviruses to HS usually results in smaller plaque size under agar, more rapid clearance from the blood, and higher neurovirulence when inoculated directed into the brain of mice [16,24-27]. Here, we show that the mutants with partial HS-dependent phenotype in comparison to XJ-160 caused bigger plaques on BHK-21 cells and exhibited less neurovirulent in suckling mice than parental virus did. As shown in Figure 3, similar to XJ-160 virus is that all the mutants showed fatal neurovirulence in suckling mice. However, XJ-160 virus killed all animals about 7 days after inoculation. In contrast, BR-146 H, BR-149R and BR-HR only killed $50 \%, 40 \%$ and $80 \%$ of mice 10 days after inoculation (Figure 3). Consistence with our data is that the increased binding to cellular HS is associated with loss of neurovirulence of Murray Valley encephalitis virus [28]. In contrast, decreased HS binding resulted in loss of neurovirulence of Theilers murine encephalomyelitis virus [29]. The distinct effects of HS-binding on viral neurovirulence suggest that the two parameters are relatively separable, and that other properties of the virus play an important role for viral neurovirulence.

\section{Additional material}

Additional file 1: Figure 1 Infectivity of the mutant viruses in BHK21 cells. Cytopathic effect (CPE) 36 h postinfection (p.i.) (upper panels), IFA 48 h p.i. (middle panels), and plaque-forming assay $24 \mathrm{~h}$ p.i. (lower panels) of parental virus and the mutants were observed in BHK-21 cells.

Additional file 2: Figure 2 Growth curves of mutant viruses and the parental viruses. Monolayer of BHK- 21 cells at $80 \%$ confluency was infected with parental viruses and recombinant viruses at a multiplicity of infection of 0.01 . The medium (1 ml) was removed on hours $20,24,28$, 32,36 and $44 \mathrm{~h} \mathrm{p}$. i., and frozen for later determination of virus titers, and equal volume of fresh medium was added. The virus titers are shown as the mean \pm SD of 3 replicate experiments.

\footnotetext{
Acknowledgements

This work was supported by the grants from the National Natural Science Foundation of China (No. 30970160), the Major Science and Technology Project for Infectious Disease (No. 2008ZX10004-001; 2009ZX10004-705), the Development Grant of State Key Laboratory for Infectious Disease Prevention and Control (2008SKLID105) and the Swedish Research Council (K2009-67X21128-01-3).
}

\section{Author details}

${ }^{1}$ State Key Laboratory for Infectious Disease Prevention and Control (SKLID), Institute for Viral Disease Control and Prevention, China CDC, Beijing, China. ${ }^{2}$ Department of Medical Biochemistry and Microbiology, University of Uppsala, The Biomedical Center, Uppsala, Sweden.

\section{Authors' contributions}

WZ carried out the molecular genetic studies, participated in the sequence alignment and drafted the manuscript. SF carried out the immunoassays. YH participated in the sequence alignment. JL participated in the design of the study and performed the statistical analysis. GL conceived of the study, and participated in its design and coordination. All authors read and approved the final manuscript.

\section{Competing interests}

The authors declare that they have no competing interests.

Received: 29 July 2010 Accepted: 14 September 2010 Published: 14 September 2010

\section{References}

1. Taylor RM, Hurlbut HS, Work TH, Kingsbury JR, Frothingham TE: Sindbis virus: a newly recognized arthropod-transmitted virus. Am J Trop Med Hyg 1955, 4:844-846.

2. Doherty RL, Carley JG, Kay BH, Filippich C, Marks EN, Frazier CL: Isolation of virus strains from mosquitoes collected in Queensland 1972-1976. Aust. J Exp Biol Med Sci 1979, 57:509-520.

3. Strauss JH, Strauss EG: The alphaviruses: gene expression, replication, and evolution. Microbiol Rev 1994, 58:491-562.

4. Liang GD, Li L, Zhou GL, Fu SH, Li QP, Li FS, He HH, Jin Q, He Y, Chen BQ Hou YD: Isolation and complete nucleotide sequence of a Chinese Sindbis-like virus. J Gen Virol 2000, 81:1347-1351.

5. Zhou GL, Liang GD, Li L, Fu SH, Zhang HL: Sequencing analysis of the genome of YN87448 virus, first isolated in China. Zhonghua Shi Yan He Lin Chuang Bing Du Xue Za Zhi 1998, 12:81.

6. Byrnes AP, Griffin DE: Binding of Sindbis virus to cell surface heparan sulfate. J Virol 1998, 72:7349-7356.

7. Klimstra WB, Ryman KD, Johnston RE: Adaptation of Sindbis virus to BHK cells selects for use of heparan sulfate as an attachment receptor. J Virol 1998, 72:7357-7366.

8. Bernard KA, Klimstra WB, Johnston RE: Mutations in the E2 glycoprotein of Venezuelan equine encephalitis virus confer heparan sulfate interaction, low morbidity, and rapid clearance from blood of mice. Virology 2000, 276:93-103.

9. Heil ML, Albee A, Strauss JH, Kuhn RJ: An amino acid substitution in the coding region of the E2 glycoprotein adapts Ross River virus to utilize heparan sulfate as an attachment moiety. J Virol 2001, 75:6303-6309.

10. WuDunn, Spear PG: Initial interaction of herpes simplex virus with cells is binding to heparan sulfate. J Virol 1989, 63:52-58.

11. Patel M, Yanagishita M, Roderiquez G, Bou-Habib DC, Oravecz T, Hascall VC, Norcross MA: Cell-surface heparan sulfate proteoglycan mediates HIV-1 infection of T-cell lines. AIDS Res Hum Retroviruses 1993, 9:167-174.

12. Summerford C, Samulski RJ: Membrane-associated heparan sulfate proteoglycan is a receptor for adeno-associated virus type 2 virions. J Virol 1998, 72:1438-1445.

13. Krusat T, Streckert HJ: Heparin-dependent attachment of respiratory syncytial virus (RSV) to host cells. Arch Virol 1997, 142:1247-1254.

14. Jackson T, Ellard FM, Ghazaleh RA, Brookes SM, Blakemore WE, Corteyn AH, Stuart DI, Newman JW, King AM: Efficient infection of cells in culture by type $O$ foot-and-mouth disease virus requires binding to cell surface heparan sulfate. J Virol 1996, 70:5282-5287.

15. Joyce JG, Tung JS, Przysiecki CT, Cook JC, Lehman ED, Sands JA, Jansen KU, Keller PM: The L1 major capsid protein of human papillomavirus type 11 recombinant virus-like particles interacts with heparin and cell-surface glycosaminoglycans on human keratinocytes. J Biol Chem 1999, 274:5810.

16. Zhu W, Wang L, Yang Y, Jia J, Fu S, He Y, Li JP, Liang G: Interaction of E2 Glycoprotein with Heparan Sulfate Is Crucial for Cellular Infection of Sindbis Virus. PLoS ONE 2010, 5(3):e9656. 
17. Zhu WY, Yang YL, Fu SH, Wang LH, Zhai YG, Tang Q, Liang GD: Substitutions of 169Lys and 173Thr in nonstructural protein 1 influence the infectivity and pathogenicity of XJ-160 virus. Arch Virol 2009, 154:245-253.

18. Mitchell KJ, Pinson KI, Kelly OG, Brennan J, Zupicich J, Scherz P, Leighton PA, Goodrich LV, Lu X, Avery BJ, Tate P, Dill K, Pangilinan E, Wakenight $P$, Tessier-Lavigne M, Skarnes WC: Functional analysis of secreted and transmembrane proteins critical to mouse development. Nat Genet 2001, 28:241-249.

19. Li JP, Gong F, Hagner-McWhirter Å, Forsberg E, Åbrink M, Kisilevsky R, Zhang $\mathrm{X}$, Lindahl U: Targeted disruption of a murine glucuronyl C5epimerase gene results in heparan sulfate lacking L-iduronic acid and in neonatal lethality. J Biol Chem 2003, 278:28363-28366.

20. Yamada S, Busse M, Ueno M, Kelly OG, Skarnes WC, Sugahara K, KuscheGullberg M: Embryonic fibroblasts with a gene trap mutation in Ext1 produce short heparan sulfate chains. J Biol Chem 2004, 279:32134-32141.

21. Jia J, Maccarana M, Zhang X, Bespalov M, Lindahl U, Li JP: Lack of Liduronic acid in heparan sulfate affects interaction with growth factors and cell signaling. J Biol Chem 2009, 284:15942-15950.

22. Kakkar AK, Levine MN, Kadziola Z, Lemoine NR, Low V, Patel HK, Rustin G, Thomas M, Quigley M, Williamson RC: Low molecular weight heparin, therapy with dalteparin, and survival in advanced cancer:the fragmin advanced malignancy outcome study (FAMOUS). J Clin Oncol 2004, 22:1944-1948.

23. Desai UR, Wang HM, Linhardt RJ: Specificity studies on the heparin lyases from Flavobacterium heparinum. Biochemistry 1993, 32:8140-8145.

24. Bear JS, Byrnes AP, Griffin DE: Heparin-binding and patterns of virulence for two recombinant strains of Sindbis virus. Virology 2006, 347:183-190.

25. Byrnes AP, Griffin DE: Large-plaque mutants of Sindbis virus show reduced binding to heparin sulfate, heightened virema, and slower clearance from circulation. J Virol 2000, 74:644-651.

26. Klimstra WB, Ryman KD, Bernard KA, Nguyen KB, Biron CA, Johnston RE: Infection of neonatal mice with sindbis virus results in a systemic inflammatory response syndrome. J Virol 1999, 73:10387-10398.

27. Ryman $\mathrm{KD}$, Gardner $\mathrm{CL}$, Burke CW, Meier KC, Thompson JM, Klimstra WB Heparan sulfate binding can contribute to the neurovirulence of neuroadapted and nonneuroadapted Sindbis viruses. J Virol 2007 81:3563-3573.

28. Lee $E$, Lobigs $M$ : Substitutions at the putative receptor-binding site of an encephalitic flavivirus alter virulence and host cell tropism and reveal a role for glycosaminoglycans in entry. J Virol 2000, 74:8867-8875.

29. Reddi HV, Manoj Kumar AS, Kung AY, Kallio PD, Schlitt BP, Lipton HL: Heparan sulfate-independent infection attenuates high-neurovirulence GDVII virus-induced encephalitis. J Virol 2004, 78:8909-8916.

doi:10.1186/1743-422X-7-225

Cite this article as: Zhu et al:: Amino acid substitutions in the E2 glycoprotein of Sindbis-like virus XJ-160 confer the ability to undergo heparan sulfate-dependent infection of mouse embryonic fibroblasts. Virology Journal 2010 7:225.

\section{Submit your next manuscript to BioMed Central and take full advantage of:}

- Convenient online submission

- Thorough peer review

- No space constraints or color figure charges

- Immediate publication on acceptance

- Inclusion in PubMed, CAS, Scopus and Google Scholar

- Research which is freely available for redistribution

Submit your manuscript at www.biomedcentral.com/submit
Biomed Central 